\title{
Doxycycline Hyclate Injection
}

National Cancer Institute

\section{Source}

National Cancer Institute. Doxycycline Hyclate Injection. NCI Thesaurus. Code C125186.

An injectable formulation composed of the hyclate salt form of doxycycline, a synthetic, broad-spectrum tetracycline antibiotic, with antimicrobial activity. Upon injection, doxycycline reversibly binds to the bacterial 30 S ribosomal subunit, and blocks the binding of aminoacyl-tRNA to the mRNA-ribosome complex. This leads to an inhibition of bacterial protein synthesis and abrogates bacterial infections. 